\title{
A Case of Idiopathic REM Sleep Behaviour Disorder Suspected Presymptomatic Stage of Neurodegenerative Disorders
}

\author{
Jin-Won Bae ${ }^{1}$, Jae-Wook Cho ${ }^{2}$, Dae-Jin $\mathrm{Kim}^{2}$, Chul Hyoung Lyoo $^{3}$ and Jae-Hyeok Lee ${ }^{2}$ \\ ${ }^{1}$ Department of Neurology, Pusan National University Hospital, Busan, \\ ${ }^{2}$ Department of Neurology, Pusan National University Yangsan Hospital, Yangsan, \\ ${ }^{3}$ Department of Neurology, Yonsei University College of Medicine, Seoul, Korea
}

\author{
신경퇴행성 질환의 전 증상으로 여겨지는 특발성 렘수면 행동 장애 1예 \\ 배진원 ${ }^{1}$, 조재욱 ${ }^{2}$, 김대진 $^{2}$, 류철형 ${ }^{3}$, 이재혁 ${ }^{2}$ \\ 부산대학교병원 신경과, ${ }^{1}$ 양산부산대학교병원 신경과, ${ }^{2}$ 연세대학교 의과대학 신경과학교실 ${ }^{3}$
}

\begin{abstract}
Received April 28, 2011
Revised June 1, 2011

Accepted June 8, 2011
\end{abstract}

Address for correspondence

Jae-Hyeok Lee, MD

Department of Neurology,

Pusan National University

Yangsan Hospital,

Beomeo-ri, Mulgeum-eup,

Yangsan 626-770, Korea

Tel: +82-55-360-2453

Fax: $+82-55-360-2152$

E-mail: jhlee.neuro@pusan.ac.kr
REM sleep behavior disorder (RBD) may be idiopathic or associated with various neurodegenerative disorders such as parkinsonian disorders. We report here a patient diagnosed as idiopathic RBD. He had additional clinical features such as anosmia and various autonomic dysfunctions. FP-CIT PET imaging showed reduced bilateral striatal dopamine transporter binding uptake. These findings suggest that patients with idiopathic RBD can have various clinical features seen in parkinsonian disorders beyond sleep complaint.

J Korean Sleep Res Soc 2011;8:14-16

Key Words: REM sleep behavior disorder, Dopamine transporter, Neurodegenerative diseases.
렘수면 행동 장애(REM sleep behaviour disorder, RBD) 는 렘수면 중 정상적으로 발생하는 근육 긴장의 소실이 나타 나지 않는 것을 특징으로 하며, 렘수면 동안 꿈의 내용을 행 동으로 나타내고 과격한 행동이나 소리지르는 모습을 보인 다. ${ }^{1}$ 다른 질환의 증거가 없는 특발성(idiopathic RBD)과 신 경계 질환에 동반된 증후성(symptomatic RBD)으로 나뉘며, 증후성의 경우 파킨슨병, 다계통위축증, 루이체치매와 같은 시누클레인병증(synucleinopathy)에서 잘 동반된다. ${ }^{2}$

저자들은 다른 신경퇴행성 질환으로 진단된 적이 없는 특 발성 $\mathrm{RBD}$ 환자에게서 후각상실(anosmia), 자율신경계 기능이 상, 그리고 $\mathrm{FP}-\mathrm{CIT}$ 양전자방출단층촬영(positron emission tomography, PET)검사 상 양측 선조체(striatum)에서 도파민 운반체의 감소 소견을 관찰하고 이의 임상적 의의를 보고하 고자 한다.

\section{증 례}

58세 남자 환자가 5년 전부터 수면 중 누군가와 싸우는 듯 주먹을 휘두르거나 안경을 옥수수로 착각하여 씹는 등의 이 상 행동이 보호자에 의해 자주 목격되었다. 그리고 비슷한 시기부터 냄새를 잘 맡지 못하고 음식 맛을 제대로 구분하지 못하였다. 변비가 있어 간헐적으로 하제를 복용하였고, 최근 들어 앉았다가 일어나면 어지럼증이 생겼다. 내원 당시 특별 히 복용하고 있는 약은 없고, 인지 기능을 포함한 신경학적 검사에서도 특이 사항은 없었다. 일반혈액검사 또한 정상 범 주였다. 렘수면 행동 장애를 의심하고 이에 대한 확인 위해 야간 수면다원검사(polysomnography)를 실시한 결과 평소 수면 시간이 4시간 정도 밖에 되지 않았는데, 검사 당일에도 야간 총 수면 시간은 177분이었고 수면효율은 $77 \%$ 였다. 수 면 중 비교적 잦은 각성(arousal index 15.0/hr)을 보였고 수 


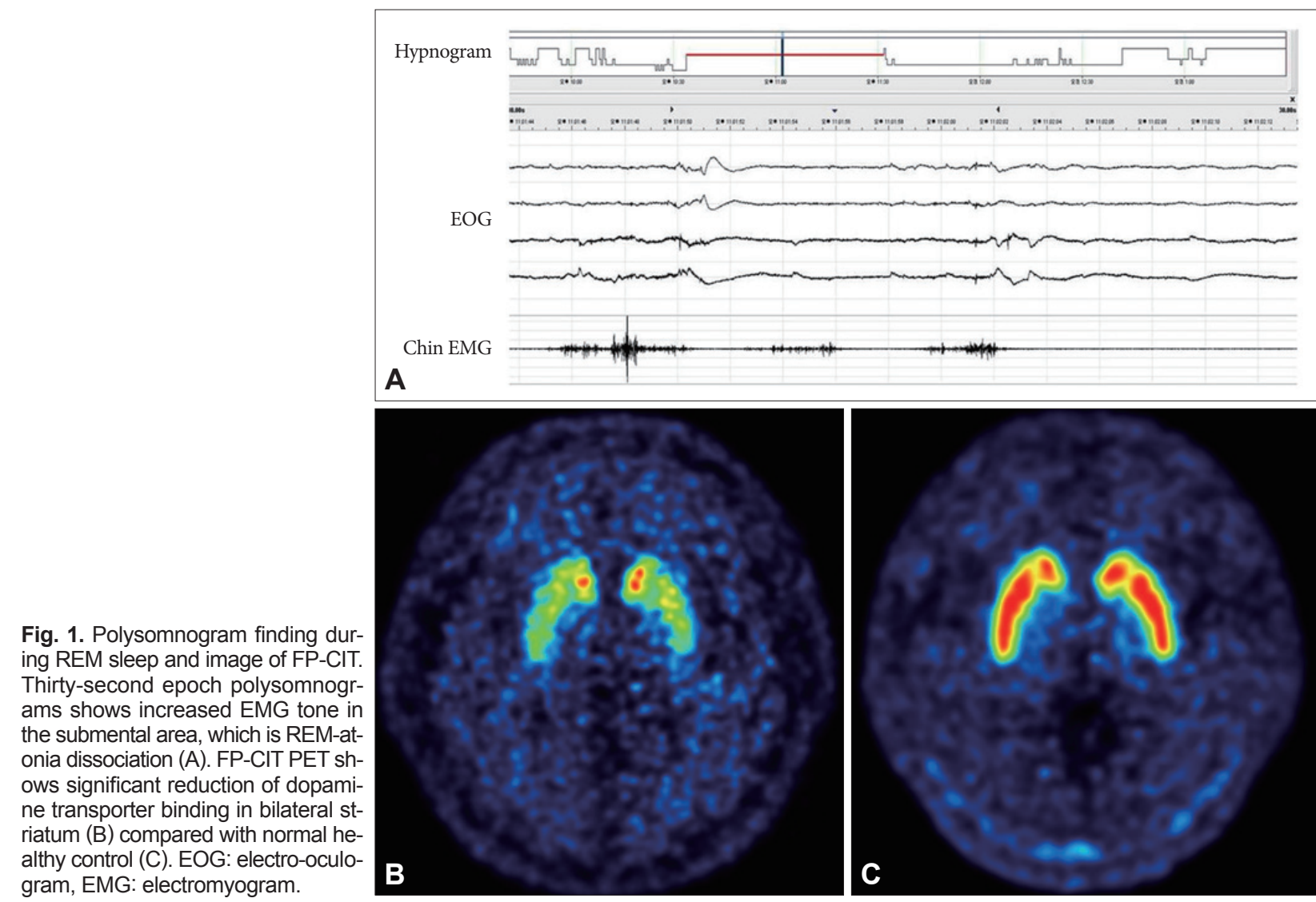

면 잠복기는 2.8 분으로 단축되어 있었으나 렘수면잠복기는 77.0분으로 정상범위였다. 무호흡 저호흡 지수(Apnea hypopnea index)는 1.4/ hr였다. 수면 구조에서는 N1, N2수면은 각각 $13.8 \%, 50.3 \%$ 로 N1은 증가, N2는 정상이었으나, N3수 면이 $3.1 \%$ 로 감소하였고, 렘수면이 $32.8 \%$ 로 증가된 양상이 었다. 렘수면 중 뭔가 꿈을 꾸는 듯 중얼거리면서 양팔을 휘 젓는 동작이 2회 있었는데 다음 날 환자는 본인의 행동에 대 해 기억하지 못했다.

이런 증상은 3 5분 정도 지속되었고 턱 근긴장의 증가(REM sleep without atonia)를 동반하였다. 이상행동이 없는 렘수면 동안에도 턱 근전도 진폭(amplitude)이 비렘수면(NREM sle$\mathrm{ep}$ )때의 최소 진폭에 비해 더 크게 나타나는 소견이 자주 관 찰되었다(Fig. 1A).

수면다원검사 결과가 AASM scoring manual, 2007 진단 기 준을 충족하여 렘수면 행동 장애로 확진하고 클로나제팜(Clonazepam) 투여 후 증상은 호전되었다. 한국형 후각 검사 $\mathrm{KV}-$ SS-II 상 후각 역치검사 $2 / 16$, 후각 식별검사 $6 / 16$, 후각 인지 검사 $7 / 16$ 으로 TDI score가 15/48로 후각상실에 해당되었다. 기립경 테이블 검사에서 뚜렷한 기립성 저혈압 소견(5분간 침상 안정 시: $110 / 60 \mathrm{mmHg}, 55$ 회/분, 기립 3분 후: 80/55 $\mathrm{mmHg}, 64$ 회/분)을 보였다.
뇌 MRI에서의 이상 소견은 없었고, 시행한 FP-CIT PET에 서 양측 선조체에서 섭취의 저하 소견이 관찰되었다(Fig. 1B). 이후 2년간 추적 관찰하였으나 파킨슨증(Parkinsonism)을 포함한 다른 신경퇴행성 질환을 시사하는 임상소견은 발생 하지 않았다.

\section{고 찰}

본 증례는 신경퇴행성 질환의 전형적인 증상 및 징후 없이 발생한 $\mathrm{RBD}$ 로 파킨슨증이 나타나는 질환들에서 흔한 후각 상실과 자율신경계 이상 증상이 동반되었다. 최근 연구 결과 에 의하면 특발성 RBD 환자에서도 후각 장애, 자율신경계 장애, 시공간 구성 장애, 인지기능 장애 등이 잦으며 이러한 증상들이 동반될 수록 추후 신경퇴행성질환으로 이환이 더 잘 된다고 한다. ${ }^{3,4}$

Schenck 등5은 특발성 RBD로 생각되었던 환자 29명을 약 6년간 추적한 결과, 11 명(38\%)에서 파킨슨증이 발생했음을 보고하였다. 이후 다른 연구진도 44 명의 특발성 $\mathrm{RBD}$ 환자 를 5년 관찰한 결과, $45 \%$ 에서 특발성 파킨슨병, 다계통위축 증, 루이체치매를 포함하는 신경퇴행성질환으로의 이환을 확인하였다. ${ }^{4}$ 또 다른 연구에서는 $\mathrm{RBD}$ 증상 시작 후 5 년에는 
$17 \%, 10$ 년에는 $40 \%, 12$ 년에서 $52 \%$ 정도의 환자에서 이들 퇴행성 질환이 발병하는 것으로 보고하였다. ${ }^{1}$ 결론적으로 특 발성 $\mathrm{RBD}$ 환자들의 상당수에서 파킨슨증과 연관된 질환들 이 발병한다는 보고들과 이러한 질환들에서 확인되는 다양 한 임상 소견들이 특발성 RBD에서도 동반되는 사실들로 미 루어 볼 때, 특발성 $\mathrm{RBD}$ 가 독립적인 질환이 아닌 퇴행성 질 환 특히 파킨슨증과 연관된 질환들의 전구 증상일 가능성이 높다는 추측을 하게 한다.

특발성 $\mathrm{RBD}$ 나 후각 장애 환자들 중 일부에서 선조체의 도 파민 운반체 감소가 관찰되었고 이 환자들의 추적 관찰에서 일부가 임상적으로 파킨슨병으로 진단되었다., ${ }^{4,6}$ 본 증례에서 는 $\mathrm{RBD}$ 와 더불어 후각상실과 자율신경계 장애 증상이 동반 되었고, $\mathrm{FP}-\mathrm{CIT} \mathrm{PET}$ 검사상 도파민 운반체의 현저한 감소 를 보였다. 만일 환자가 추후 파킨슨병으로 진행된다면, 현 시점은 임상적으로 파킨슨병의 운동 전단계(premotor stage of Parkinson's disease)에 해당될 것이다. 하지만 다른 시누 클레인병증인 다계통위축증이나 루이체치매로 진행할 가능 성도 배제할 수 없으므로 추후 임상적 경과 관찰이 필요할 것이다.

\section{Acknowledgments}

본 연구는 2010년도 양산부산대학교병원 임상연구비 지원으로 이 루어 졌음.

\section{REFERENCES}

1. Postuma RB, Gagnon JF, Vendette M, Fantini ML, Massicotte-Marquez J, Montplaisir J. Quantifying the risk of neurodegenerative disease in idiopathic REM sleep behavior disorder. Neurology 2009;72:1296-1300.

2. Boeve BF, Silber MH, Ferman TJ, Lucas JA, Parisi JE. Association of REM sleep behavior disorder and neurodegenerative disease may reflect an underlying synucleinopathy. Mov Disord 2001;16:622-630.

3. Iranzo A, Molinuevo JL, Santamaría J, et al. Rapid-eye-movement sleep behaviour disorder as an early marker for a neurodegenerative disorder: a descriptive study. Lancet Neurol 2006;5:572-577.

4. Siderowf A, Stern MB. Premotor Parkinson's disease: clinical features, detection, and prospects for treatment. Ann Neurol 2008;64 Suppl 2: S139-S147.

5. Schenck CH, Bundlie SR, Mahowald MW. Delayed emergence of a parkinsonian disorder in $38 \%$ of 29 older men initially diagnosed with idiopathic rapid eye movement sleep behaviour disorder. Neurology 1996; 46:388-393.

6. Eisensehr I, Linke R, Noachtar S, Schwarz J, Gildehaus FJ, Tatsch K. Reduced striatal dopamine transporters in idiopathic rapid eye movement sleep behaviour disorder. Comparison with Parkinson's disease and controls. Brain 2000;123:1155-1160. 